Exilés de l'intime: la médécine et la psychiatrie au service du nouvel ordre économique Roland Gori et M.-J. Del Volgo Paris: Denoël, 2008, 344 págs.

\title{
A saúde mental e a razão sanitária
}

\begin{abstract}
"Exilados do íntimo" é a fórmula pela qual Roland Gori e Marie-José Del Volgo buscam, em seu último livro, traduzir a condição pática do que chamam "o homem neuroeconômico" contemporâneo. $\mathrm{O}$ texto retoma as temáticas da medicalização da existência e da redução, pela medicina atual, da experiência do adoecer a suas coordenadas biológicas, objetiváveis, cujas conseqüências já haviam sido tratadas em sua obra precedente, de 2005, intitulada La santé totalitaire. ${ }^{1}$ Desta vez, contudo, a crítica endereça-se mais especificamente à psiquiatria. Esta, desnaturada em suas relações éticas com o Estado pela ideologia da saúde mental e solicitada a deliberar desde uma posição de autoridade científica absoluta sobre os fundamentos das paixões e comportamentos humanos, termina por participar de forma cada vez mais ativa da alienação dos sujeitos em relação a seu próprio sofrimento. Correlativamente, suas intervenções concretas, comprometidas com a normalização valorativa de certos comportamentos considerados desviantes à luz
\end{abstract}

1. Gori, R. \& Del Volgo, M.-J. La santé totalitaire. Essai sur la médicalisation de l'existence. Paris: Denoël, 2005. 
de uma concepção do humano marcada pelo capitalismo liberal contemporâneo, tendem a inseri-los "em redes de conformação das condutas" (p. 215).

Partindo de uma análise socioantropológica do papel determinante que a fusão da racionalidade biomédica com a lógica liberal capitalista atualmente exerce sobre a sociedade, os autores realizam um estudo minucioso de sua incidência sobre as formas de subjetivação propostas por essa cultura, bem como de suas repercussões sobre as configurações do laço social.

Já em Max Weber, indicam eles, é possível discernir a idéia de que a racionalidade econômica do Ocidente não é separada de seus dispositivos de interpretação do mundo. Pelo contrário, há um laço profundo que conjuga certas atitudes - e questões - psicológicas com a ação propriamente econômica. O sucesso da ação econômica, racionalmente preparada e executada, fornece - para além dos ganhos materiais - ganhos de certeza de salvação, que se instauram como "signos eletivos da graça nesse mundo da imanência" (p. 45). Em nossas sociedades contemporâneas esse "capitalismo emocional" (p. 47) coloca-se abertamente como componente fundamental da vida psíquica, fornecendo não apenas segurança material, mas sentido existencial e garantias simbólicas contra "a angústia provocada pela (descoberta) do fato de que o conhecimento de Deus é impossível". Encontrando-se desamparados no mundo, os homens contam, mesmo assim, com as certezas fornecidas pela lógica individualista capitalista e pelos postulados da ciência. A adesão maciça da psiquiatria a essa racionalidade técnico-econômico-administrativa do mundo, concluem Gori e Del Volgo, potencializa suas possibilidades de intervenção no campo sociopolítico concreto e responde - no interior dessa mesma lógica, da qual ela se faz um agente privilegiado - a alguns dos anseios e temores mais profundos dos próprios indivíduos.

Os autores denunciam, assim, uma degradação da psiquiatria na ideologia da "saúde mental". Com esse artifício retórico, psiquiatras e demais profissionais a ela ligados colocam-se a serviço da "administração sociopolítica do desvio" (p. 216).

Tratando fundamentalmente o sintoma, a psiquiatria contemporânea não se preocuparia mais em encontrar a etiologia de suas entidades diagnósticas, promovendo um descentramento do patológico em direção ao normativo (p. 217). Correlativamente, "o pathos do sofrimento psíquico encontra-se reduzido a um transtorno do comportamento" (p. 218). Assim, o caráter abertamente normativo e normalizante da noção operativa de "mental disorders", central na nosografia psiquiátrica contemporânea, tem por si só um efeito "tranqüilizante" e "reassegurante", ainda que deixe em aberto a definição da "order" que os profissionais "psi" são convocados a reestabelecer.

"O sofrimento do sujeito freudiano", diz o texto, "se revelava como um conflito trágico de um sujeito dividido em relação a si mesmo, combatendo suas pio- 
res intenções inconscientes e recusando sua realização, das quais os sintomas neuróticos não seriam senão os ersatz, os medíocres compromissos de uma contabilidade interior inteiramente modelada pela moral burguesa" (p. 229). No interior de seu processo ativo de nada querer saber sobre aquilo que lhe é insuportável, é o sujeito - enquanto tal - a sede do saber recalcado e o agente de seu próprio desconhecimento.

Já o indivíduo da saúde mental é duplamente ignorante: 1) ignora os riscos de desvio e de anormalidade que pode portar sem o saber; 2) ignora "a mecânica involuntária" (p. 229) de seus atos e sentimentos, cuja origem repousaria inteiramente na profundidade biológica e material de seu corpo. O saber sobre si próprio só poderia, dessa forma, ser aportado a partir do exterior, por um especialista, falando em nome da ciência. O sujeito necessita, portanto, ser avaliado para descartar possíveis riscos para sua saúde mental e para prevenir a eclosão de perturbações para as quais estaria biologicamente predisposto. "Prevenir e vigiar" tornam-se questões delegadas aos agentes de saúde mental, os quais respondem aos temores de uma "civilização da paranóia em relação a si próprio" (p. 231), na qual a opacidade das determinações orgânicas tornam, cada um, um portador potencial de males cuja existência se manifeste apenas discretamente no campo psíquico e comportamental. O indivíduo fica, assim, alienado da posição de sujeito de sua existência e qualquer busca de sua própria implicação no sofrimento do qual se queixa encontra-se, de antemão, desqualificada. $\mathrm{O}$ sofrimento e as paixões passam a ser vistos como uma questão estrangeira ao próprio indivíduo, como efeitos de determinações totalmente exteriores ao âmbito do sujeito: trata-se, totalitariamente, de uma questão para a ciência e para seus representantes no plano da clínica. Tal postura constituiria, aos olhos dos autores, "o verdadeiro niilismo de nossa civilização que não acredita mais na existência do íntimo, tanto quanto não crê na existência da alma".

Essa busca incessante do diagnóstico psiquiátrico de perturbações que o indivíduo pode ser portador sem desconfiar, da identificação de vulnerabilidades genéticas ou cognitivas, do levantamento de fatores de risco e a identificação precoce de comportamentos susceptíveis de expressar uma desordem psíquica, passa a fazer parte de uma racionalidade técnico-sanitária que reflete uma "medicalização da existência". Nesse contexto, não apenas é solicitada a intervenção médica concreta, como também se coloca ao indivíduo a tarefa permanente da auto-observação e do autocontrole, em uma condição de permanente escrutínio sanitário de si mesmo, balizado pelos valores bioeconômicos que delimitam as fronteiras morais entre order e disorder.

Verifica-se, assim, uma espécie de conluio em que se associam uma estruturação antropológica dos costumes em torno do saber médico e uma demanda 
efetiva de que a medicina traga respostas concretas para as dificuldades e enigmas do mal de existir.

Os autores chamam a atenção para os riscos, não suficientemente levados em conta, de que os próprios processos precoces de avaliação e de acompanhamento de populações e indivíduos com riscos possam se transformar em profecias auto-realizáveis.

Em uma crítica contundente aos esforços pragmáticos pela criação de um código lingüístico estável que permita uma relação constante, compartilhada entre os usuários do instrumento, entre uma etiqueta diagnóstica e um estado de coisas objetivável na realidade clínica, os autores sustentam, apoiados em uma proposição de Adorno, que se trata "de uma adequação lingüística àquilo que (já) está morto" (p. 336). O que talvez seja um outro modo de colocar a idéia de Nietzsche, segundo a qual nós só conseguimos falar com serenidade daquilo que já está morto dentro de nós. Trata-se, pois, de uma psicopatologia sem qualquer lugar para a paixão e, mais amplamente, para o próprio pathos humano, que não encontrando campo legítimo onde possa se expressar, fará irrupção não mais como sintoma simbolizado, mas como explosão e como passagem ao ato.

Nesse universo de alienação progressiva do sujeito em relação a si próprio e de desqualificação de sua interioridade - ou pelo menos de um campo autóctone no qual ele tenha a experiência concreta de existir - condições niilistas tomariam um papel maior na sociedade contemporânea e nos processos de subjetivação. Os autores apontam, assim, na conclusão de seu livro, os riscos de violência e de destruição como respostas individuais e coletivas a essa experiência renovada de exílio existencial em relação a si, marca do homem de nosso tempo. Pela passagem ao ato violenta, "um sujeito procura objetivar como um outro, através de um outro e sobre um outro o horror de sua própria instrumentação, o terror de sua própria reificação" (p. 335).

Através de um maciço esquadrinhamento (psico)técnico de sua existência em que cada um de seus atos ou sentimentos responde unicamente a uma determinação biológico-econômica sobre a qual o sujeito enquanto tal não se encontra minimamente implicado, permanecendo, pois, em uma posição de ser inteiramente decifrável por um saber científico que o objetivaria, sem resto - o homem neuroeconômico encontrar-se-ia privado "dos valores positivos da melancolia" (p. 22). Quando, nas sociedades totalitárias, o vazio - relativo à incompletude humana - não pode ser sustentado, o que se perde é a própria possibilidade para os sujeitos de encontrarem sua própria consistência. Citando Pierre Fédida, o texto fala da "depressividade como solo natal do psiquismo, do qual a melancolia seria a doença da espécie" (p. 23). Para Lacan, é justamente a incompletude do processo de alienação que permite, através do resto que este engendra, a 
instauração de um sujeito do desejo no campo de sua fantasia. A ideologia neuroeconômica contemporânea, por sua vez, propõe "a cura da falta" pela supressão do resto: o homem é objetivável enquanto tal pela ciência e esta pode colocar no mercado os remédios para seus males, que, em última instância, não passariam de sensações de mal-estar ou de comportamentos sintomáticos redutíveis a fragilidades biológicas, objetivamente desmistificadas pelas autoridades científicas.

Como pano de fundo de todo esse debate está uma tomada de posição ética segundo a qual o pathos humano é irredutível às categorias médicas de "lesão" e de "disfunção", cabendo à clínica, a sustentação e o acolhimento da palavra autóctone, na qual o sujeito possa se reconhecer e, eventualmente, terapeuticamente, começar a se reconstruir e se ressituar. Tal, pois, parece ser o sentido da contundente frase de Roland Gori e de Marie-José Del Volgo, que nos alertam para que não esqueçamos o valor próprio e insubstituível da palavra singular, seja para a prática clínica, seja para o avanço da ciência ou, ainda, para o constante reengendramento das bases do laço social, o qual nos faz humanos: “... é conveniente se conferir um lugar ao valor ethopoiético da palavra, para que a sobrevivência da espécie não extermine sua humanidade" (p. 18).

\section{Mário Eduardo Costa Pereira}

Psiquiatra; psicanalista e professor do Depto. de Psicologia Médica e Psiquiatria da Universidade Estadual de Campinas - Unicamp (Campinas, SP, Brasil); doutor em Psicopatologia Fundamental e Psicanálise pela Universidade Paris 7 (Paris, França); diretor do Laboratório de Psicopatologia Fundamental da Unicamp; professor do Departamento de Psicanálise do Instituto Sedes Sapientiae (São Paulo, SP, Brasil); membro da Associação Universitária de Pesquisa em Psicopatologia Fundamental (São Paulo, SP, Brasil); autor dos livros Pânico e desamparo (São Paulo: Escuta, 1999) e Psicopatologia dos ataques de pânico (São Paulo: Escuta, 2003).

Rua Carolina Prado Penteado, 725 - Nova Campinas

13092-470 Campinas, SP, Brasil

Fone: (19) 3254-5064 / 3254-1982 / 3289-4819 (Unicamp)

e-mail: marioecpereira@uol.com.br 